\title{
VERIFICAÇÃO DA QUALIDADE MICROBIOLÓGICA DE REQUEIJÕES E ESPECIALIDADES LÁCTEAS
}

\author{
ASSESSING THE MICROBIOLOGICAL QUALITY OF “REQUEIJÃO" AND \\ “ESPECIALIDADE LÁCTEA"
}

\author{
J. O. HACHIYA ${ }^{1}$, G. A. M. ROSSI ${ }^{1}$, R. A. SATO ${ }^{1}$, H. O. $\operatorname{SILVA}^{1}{ }^{*}$, A. M. C. VIDAL ${ }^{2}$, L. A. AMARAL ${ }^{1}$
}

\section{RESUMO}

Staphylococcus coagulase positivos e coliformes termotolerantes são microrganismos indicadores cuja presença nos alimentos indicam a presença de práticas de higiene inadequadas durante o processamento. A presença desses indicadores com populações acima dos limites aceitáveis pela legislação vigente (RDC $\mathrm{n}^{\mathrm{o}} 12$ da ANVISA) representa risco à saúde dos consumidores, devido à possível presença de microrganismos patogênicos ou toxinas pré-formadas. Assim, este estudo objetivou avaliar a qualidade microbiológica pela quantificação de microrganismos indicadores de requeijões e especialidades lácteas normais e lights comercializados na Região do Município de Jaboticabal, Estado de São Paulo. Foram adquiridas em supermercados da região do município, 50 amostras de cada produto (especialidade láctea tradicional, especialidade láctea light, requeijão tradicional e requeijão light). Posteriormente, $25 \mathrm{~g}$ de cada amostra foi adicionada em frascos contendo $225 \mathrm{ml}$ de água peptonada $0,1 \%$ esterilizada e foram realizadas as demais diluições decimais até $10^{-3}$. Os tubos de LST foram semeados com as três diluições e incubados por $48 \mathrm{~h}$ a $35^{\circ} \mathrm{C}$. Dos tubos de LST que apresentaram turvação e produção de gás foi transferida uma alçada para tubos contendo caldo EC e incubados a $44,5^{\circ}$ por $24 \mathrm{~h}$. Também, $0,2 \mathrm{ml}$ da diluição $10^{-1}$ foi semeada em placas com ágar Baird Parker, e foi realizada a contagem nas placas que apresentaram colônias típicas e que na coloração pelo método Gram revelaram cocos gram-positivo. Posteriormente, foi feito o teste de coagulase. Das 200 amostras analisadas apenas uma delas apresentou resultado positivo para coliformes termotolerantes, com o valor de 2,8 NMP. $\mathrm{g}^{-1}$. Todas as amostras apresentaram resultado negativo para Staphylococcus coagulase positivos. Conclui-se que os produtos estão em condições sanitárias satisfatórias de acordo com os padrões legais estabelecidos pela RDC $n^{\circ} 12$ da ANVISA e, portanto, adequados para consumo humano. Possivelmente, isso se deve às boas práticas de higiene adotadas pelas indústrias e ao controle de temperaturas durante o processamento.

PALAVRAS-CHAVE: COLIFORMES TERMOTOLERANTES. DERIVADOS LÁCTEOS. DOENÇAS TRANSMITIDAS POR ALIMENTOS (DTA). MICROBIOLOGIA DE ALIMENTOS. Staphylococcus spp.

AGÊNCIA FOMENTO: FAPESP- Bolsa de IC - Processo 14/21534-6

ÁREA TEMÁTICA: Higiene e Inspeção de Produtos de Origem Animal;

\footnotetext{
${ }^{1}$ Instituição: 1Unesp - Universidade Estadual Paulista "Julio de Mesquita Filho" (UNESP), Faculdade de Ciência Agrárias e Veterinárias (FCAV), Via de acesso Paulo Castellane, s/n, Jaboticabal, São Paulo, Brasil, CEP 14884-900, ${ }^{2}$ Universidade de São Paulo (USP), Faculdade de Zootecnia e Engenharia de Alimentos (FZEA), Avenida Duque de Caxias Norte 225, Pirassununga, São Paulo, Brasil, CEP 13635-900.

*higorvet@yahoo.com.br
} 